BULLETIN Bulletin hispanique

HispaniQuE Université Michel de Montaigne Bordeaux

114-1 | 2012

Varia

\title{
Parodia e innovación en la primera etapa de la obra de Pérez de Ayala (1902-1913)
}

Álvaro A. Ayo

\section{CpenEdition}

Journals

Edición electrónica

URL: http://journals.openedition.org/bulletinhispanique/1905

DOI: 10.4000/bulletinhispanique.1905

ISSN: 1775-3821

Editor

Presses universitaires de Bordeaux

Edición impresa

Fecha de publicación: 1 junio 2012

Paginación: 367-381

ISBN: 978-2-86781-812-7

ISSN: 0007-4640

\section{Referencia electrónica}

Álvaro A. Ayo, « Parodia e innovación en la primera etapa de la obra de Pérez de Ayala (1902-1913) », Bulletin hispanique [En línea], 114-1 | 2012, Publicado el 01 junio 2015, consultado el 03 mayo 2019.

URL : http://journals.openedition.org/bulletinhispanique/1905; DOI : 10.4000/bulletinhispanique.1905 


\title{
Parodia e innovación en la primera etapa de la obra de Pérez de Ayala (1902-1913)
}

\author{
Álvaro A. Ayo \\ University of Tennessee, Knoxville - USA
}

Dans ses premiers récits (1902-1913), Pérez de Ayala utilise la parodie - entendue dans son double sens étymologique de distance et de rapprochement - autant pour mettre en question les conventions de la tradition littéraire au sein desquelles il commence à écrire que pour contribuer à leur enrichissement. C'est avec un lecteur moderne que Pérez de Ayala souhaite dialoguer, un lecteur disposé à accepter le défi lancé par un texte littéraire polyphonique et artistique, au-delà des objectifs référentiels du Réalisme.

En sus primeros relatos (1902-1913), Pérez de Ayala se vale de la parodia, en su ambivalente sentido etimológico de alejamiento y acercamiento, tanto para cuestionar las convenciones de la tradición literaria en que surge como para aportar a su enriquecimiento. Ayala desea entablar un diálogo con un lector moderno que esté dispuesto a aceptar el desafio que supone la forma multivoca del texto literario como creación artística, más allá de las pretensiones referencialistas del Realismo.

Pérez de Ayala's early narratives (1902-1913) rely on parody - in its ambivalent etymological sense of getting closer to and away from - both to question the conventions of the literary tradition within which he is beginning to write as to contribute to its enrichment. Ayala attempts a dialogue with a modern reader willing to be challenged by the multi vocal form of the literary text as an artistic creation, beyond the referential pretensions of Realism.

Mots-clés : Pérez de Ayala, 1902-1913, parodie, autobiographie.

$\mathrm{E}$ N la primera novela de Ramón Pérez de Ayala (1880-1962), Trece dioses (Fragmentos de las memorias de Florencio Flórez), de 1902, se aprecian dos aspectos que caracterizan su producción durante los primeros lustros del siglo XX. El primero es su aplicación de innovadores modos de expresión peleados con las convenciones decimonónicas, señaladamente, la estructura narrativa no lineal y la inclusión de capítulos aparentemente prescindibles, prueba de 
su afición por la intercalación de divagaciones ensayísticas ${ }^{1}$. El segundo es su interés por la forma autobiográfica, evidente en el título de la primera novela. Dicho interés, que también presenta lúdicas innovaciones, continúa en Sonreía (1906) y culmina en las cuatro partes del ciclo de Alberto Díaz de Guzmán, las cuales conforman la llamada tetralogía autobiográfica y son publicadas entre 1907 y 1913. Ambos aspectos son reacciones a los muchos estímulos intelectuales, literarios y artísticos que surgen en los años de entresiglos y con los que se sintoniza Ayala. No obstante, Ayala no sólo reacciona a la literatura anterior, sino que en estas primeras obras expone asimismo su admiración por la tradición literaria espańola en particular y por la occidental en general. A su vez, se vale de la forma autobiográfica para personalizar la exploración de obras, autores y géneros literarios. Al hacerlo convierte esta práctica en una verdadera búsqueda artística individual y en un profundo análisis de la época.

Resulta, pues, significativo centrarse en el modo en que Ayala se relaciona con la tradición literaria que lo antecede a través de sus innovadores recursos narrativos y de su lúdico uso de la autobiografía, dos aspectos que no han sido considerados en conjunto previamente. El autor asturiano simultanea, paradójicamente, la intención de encontrar su lugar en dicha tradición y el cuestionamiento irónico de la misma, en lo que podría considerarse un ejemplo de la ansiedad de la influencia ${ }^{2}$. Dicho de otro modo, se trata de la lucha del autor tardío por abrirse campo entre sus antecesores. Para entender debidamente esta lucha es preciso considerar el concepto de parodia, no según la convencional definición burlesca del mismo, sino la etimológica, explicada por F. J. Lelièvre en su artículo "The Basis of Ancient Parody». Lelièvre indica que el prefijo griego para implica tanto acercamiento apreciativo como alejamiento crítico (p. 66). Aunque Ayala no examina este concepto en sus escritos teóricos, sin duda un etimófilo como él apreciaría la calidad ambivalente que caracteriza dicho término.

Resulta también significativo mencionar que Andrés Amorós divide la producción de Pérez de Ayala en dos etapas principales, la de la tetralogía autobiográfica (1907-1913) y la de grandes temas, a partir de Belarmino y Apolonio hasta El curandero de su honra (1921-1926), además de una etapa de transición, conformada por Tres novelas poemáticas de la vida española (1916, Amorós, p. 19). Esta atinada e influyente división realizada por Amorós se centra en las novelas, no así en los relatos más cortos, una labor emprendida por Miguel Ángel Lozano Marco (1983, p. 39). Aunque la larga lista de títulos

1. Para una discusión sobre la preponderancia de los aspectos ensayísticos sobre los narrativos en Ayala léase a Juan Ramón Prieto Jambrina (1999, p. 159) y a Andrés Amorós (1972, p. 1013). A su vez, léase a María del Carmen Bobes Naves para un estudio de los varios recursos narrativos innovadores en la tetralogía.

2. De acuerdo con Harold Bloom la labor del poeta recién llegado al mundo literario «always proceeds by a misreading of the prior poet, an act of creative correction that is actually and necessarily a misinterpretation» (The Anxiety, 1997, p. 30). «Misinterpretation» y «misreading» pueden traducirse al castellano como interpretación o lectura erradas o tergiversadoras y, como en el presente artículo, aplicarse también a la narrativa. 
que este último proporciona y examina es invaluable para la apreciación de la narrativa de Ayala en su totalidad, su exclusión de Trece dioses, novela corta también excluida por Amorós, deja un importante espacio por explorar. Con la finalidad de llenar este espacio debe hacerse hincapié en que no sólo la tetralogía sino varios escritos narrativos que Ayala publica entre 1902 y 1913, sobre todo Trece dioses y la también novela corta Sonreía, deberían formar parte de su etapa autobiográfica, por lo que se hace indispensable estudiar una porción más representativa de su producción de la época en cuestión ${ }^{3}$.

Otro aspecto prominente en estos años es el afán impugnador que Ayala exhibe con respecto a tradición literaria, de ahí que podría hablarse no sólo de una etapa autobiográfica sino de una etapa crítica, innovadora y paródica, vale decir, una etapa exploratoria durante la cual el autor asturiano descubre su medio literario desarmando objetos como el niño cuando explora, según la interpretación perezayalina del concepto de juego de Schiller (Pequeños ensayos, p. 205). Este acto de desarmar textos implica una lectura transgresora o errada de la tradición mediante la cual se subvierten las expectativas decimonónicas de una lectura única y autorcéntrica de un texto que reproduce fielmente el mundo extratextual. Dichas expectativas no se avienen al concepto moderno de texto que maneja Ayala, esto es, el texto abierto a innúmeras lecturas posibles allende la intencionalidad autorial, como lo sugiere en un importante artículo de 1910 sobre Valle-Inclán (O.C., vol. 3, p. 397). Los objetos que Ayala desarticula y subvierte paródicamente son los géneros literarios, específicas obras literarias, filosóficas y religiosas inclusive, así como los autores que lo anteceden y sus contemporáneos, incluso los críticos que lo censuran y, dando muestras de lúdicas dotes présagas, los que van a censurarlo. Mediante este juego desarmador Ayala también pone en manifiesto múltiples conexiones intertextuales, seguramente a sabiendas de que el lector moderno ideal -ese distante lector activo e incluso coautorial, distinto al pasivo lector decimonónico (quizás no menos ideal)- inevitablemente realizará otras que el autor no puede prever.

\section{LOS PRIMEROS PASOS (I902-I906): LA PARODIA Y LA FORMA}

\section{AUTOBIOGRÁFICA}

Una de las primeras obras narrativas que Pérez de Ayala escribe y publica presenta, pues, la forma autobiográfica en la narración memorialista de un tal Florencio Flórez. Geraldine Scanlon, quien exhumara una copia de la novela Trece dioses tras 80 años durante los cuales se la había dado por perdida, destaca el vínculo con la novela de Valle-Inclán titulada Sonata de otoño. Las memorias del marqués de Bradomín (1902) tanto en la estructura como en el ambiente aristocrático y decadente que evoca (1989, p. 28). Sin embargo, más que una

3. En el presente ensayo no se incluyen muchos de los numerosos relatos que Lozano Marco incluye en su estudio debido, principalmente, a que no presentan la forma autobiográfica. 
imitación de estilo que, según Scanlon, revela una filiación modernista, la preferencia de Ayala por la forma autobiográfica revela un conato de explorar la inmediatez expresiva que la misma parece propiciar principalmente debido al empleo del yo. Al mismo tiempo el autor asturiano busca nuevas vías de expresión que trasciendan las agotadas formas decimonónicas cuestionadas por él en un artículo temprano (O.C., vol. 1, p. 1094).

A pesar de que Ayala parece ser consciente de las expectativas que la autobiografía genera en el lector corriente, señaladamente, la presencia del «yo escribiente», narrador de sus propias experiencias, da asimismo la impresión de jugar con estas expectativas, poniendo en tela de juicio dicha presencia. Por medio de la forma autobiográfica un autor puede no sólo difundir su propia voz sino también cederle la palabra a algún personaje, dos opciones que Ayala aprovecha pero también cuestiona. En Trece dioses la trama se desarrolla, ya se dijo, a lo largo de las memorias de Florencio Flórez, quien cuenta de su visita a su tío Eduardo. A la vez, en Sonreía, Fernández (verdadero apellido materno de Ayala) recibe de parte de su amigo López las memorias de Rodríguez que narran la trágica relación de éste con su novia Esperanza, siguiendo la tradición cervantina del legajo revelador. En el caso de la tetralogía, Alberto Díaz de Guzmán, presumible trasunto de Ramón Pérez de Ayala y protagonista de la serie, presenta muchos aspectos que realzan la cercanía biográfica entre el creador y su creación. No obstante, su historia está narrada en la tercera persona casi en su integridad y en sólo tres instancias se aprecia el yo de Alberto. En La pata de la raposa, las cartas que le escribe a Halconete (trasunto de Azorín) son indudablemente autobiográfico-picarescas pero es menos obvia su voz en los poemas que compone tras su crisis existencial. Entretanto, en $A$. M. D. G. se incluyen cortos pedazos del diario de Bertuco, apodo juvenil de Alberto.

El que las obras presuntamente más autobiográficas de Ayala revistan la forma menos autobiográfica ejemplifica el modo en que este autor juega con las expectativas del lector. Esta afición por lo lúdico ya se observa en Trece dioses. Por ejemplo, en el epígrafe que abre la novela se aconseja que ésta sea leída por «las almas nobles y delicadas» (1989, p. 39). En uno de los capítulos más cortos de una novela caracterizada por los capítulos cortos, se incluye la siguiente nota que prefigura capítulos prescindibles tan prominentes en la tetralogía: «Este párrafo no es más que una expansión amorosamente infantil del autor de las memorias. Pasen sin leerlo todos aquellos aficionados a seguir paso a paso al protagonista de cualquier acontecimiento» (ibid., p. 63). Ayala se dirige al lector decimonónico acostumbrado a seguir pasivamente la trama lineal de la mano del autor en pos de un nuevo tipo de lector que responda a una clase de literatura que le exige una participación activa hasta convertirlo en una especie de coautor. Este lector debería poder entender y apreciar las reglas de la narrativa decimonónica pero también disfrutar de la subversión de las mismas. Después de todo la innovación implica una lectura no necesariamente diferente sino errada de las formas preexistentes; una lectura transgresora y paródica de la tradición. 
El tópico del amor irrealizable se erige en otro aspecto unitivo de estas primeras incursiones que efectúa Ayala en la narrativa de ficción pero a un nivel diegético y temático. Florencio y su novia Justa nunca llegan a realizar su amor, sobre todo porque él vive lejos del pueblo donde reside ella. Su tío Simón tampoco consigue allegarse a su amada María debido a su condición de clérigo. En la segunda novela corta de Ayala, El último vástago (1905, no contada en forma autobiográfica pero sí a través de un narrador juguetón), el joven aristócrata Fernando Valdivares no le declara su amor a Mariana, la mujer que adora, puesto que cree que ella está enamorada del ridículo politicastro Epaminondas Gutiérrez. Pese a que Mariana ama a Valdivares, ante el silencio de éste que ella interpreta como desprecio, se casa con el grotesco personaje, mientras que Fernando muere posteriormente en un accidente ecuestre lejos del pueblo. En Sonreía, al leer las memorias de su amigo, Fernández se entera de que la sorpresiva muerte de Esperanza evita que Rodríguez alcance la felicidad amorosa con ella (O.C., vol. 1, p. 857). Estas historias acaso sirven de ensayo o antecedente de la relación entre Alberto y Fina en la tetralogía. Como Esperanza, Fina fallece mientras espera el regreso del amado, quien, al igual que Flórez, vive lejos del pueblo de ella tanto geográfica como culturalmente ${ }^{4}$.

Parecería que el motivo literario del amor irrealizable que termina trágicamente atrae al joven escritor asturiano. Esto le confiere un origen libresco a la trama, lo que evidencia que no es necesaria la preexistencia de un referente extratextual para la explicación de un texto, como se trata de establecer en el más tradicional tipo de lectura autorcéntrica, ni siquiera en obras presuntamente autobiográficas. Por ello, que Ayala hubiera tenido o no una relación aciagamente trunca como las que describe en estos relatos, tiene menos importancia que la conexión intertextual con un motivo ubicuo en la tradición occidental cuya expresión más cercana al asturiano es la romántica, en la forma de la postergación indefinida de la satisfacción amorosa. De este modo Pérez de Ayala explicita su condición de paródico mezclador de textos, consciente, además, de que en toda mezcla literaria la mayoría de los entrelazamientos con textos anteriores y contemporáneos y posibles lecturas futuras está fuera del control del autor.

\section{LA TETRALOGÍA (I907-I9I3): LA PARODIA Y LA INTERTEXTUALIDAD}

Si bien desde las primeras incursiones narrativas se observa el afán desarmador de Ayala, es en la tetralogía donde éste desarrolla con mayor frecuencia esta práctica. Como queda dicho, cada novela de la colección presenta varios objetos que Ayala desarma y subvierte de modo crítico y paródico, mayormente

4. Florencio Friera Suárez menciona el fallecimiento en 1904 de Nieves Camino, una novia asturiana de Ayala (1997, p. 49), acaso una fuente extratextual del aciago argumento. Además, consúltese el trabajo de este crítico para un exhaustivo estudio del trasfondo político de la carrera del autor asturiano. 
por medio de los recursos narrativos innovadores ya mencionados. Por ejemplo, en Tinieblas en las cumbres (1907) el enfoque son las pretensiones de reproducción fiel del Realismo y los diálogos intelectuales presentes en las novelas noventayochistas. La pata de la raposa (1912), por su parte, es una obra literaria sobre los actos de leer y de escribir que Ayala problematiza mostrándose agudamente consciente de las posibilidades y las limitaciones del texto literario. Los objetos desmontados en $A$. M. D. G. (1910) son las instituciones sociales de la familia, el sistema educativo y el clero (fijándose en el discurso ignaciano desde una perspectiva literaria), mientras que en Troteras y danzaderas (1913) lo son el mundillo literario-bohemio de la época y la excéntrica gente que lo habita. Incluso la tetralogía autobiográfica vista en bloque presenta varios objetos desarticulados y subvertidos, señaladamente, la estructura lineal prevalente en el Realismo y la ausencia casi total de un "yo escribiente».

En Tinieblas Ayala procura que el lector reconozca que se halla ante una obra ficticia, una obra de arte literaria abierta a múltiples interpretaciones y no un documento que reproduce fielmente la realidad extratextual. Esta intención se evidencia en el empleo ayalino de recursos que desvelan e ironizan las estrategias narrativas convencionales de que se vale, por ejemplo, un escritor realista, para crear la apariencia o ilusión de realidad. Uno de sus recursos más discutidos es la inclusión de «capítulos prescindibles». Así como Cervantes detiene la acción en pleno lance entre Don Quijote y el vizcaíno, estos pasajes interrumpen y fragmentan la trama central. Se indica, generalmente por medio de notas al pie de la página, que dichos pasajes no revisten mayor importancia, aunque en éstos se discuten temas que atañen a los personajes involucrados.

Entre los más comentados se halla el «Coloquio superfluo» (O.C., vol. 1, p. 179-198), un pasaje más ensayístico que narrativo de Tinieblas en que Alberto confiesa su deseo de inmortalidad. La narración del viaje de este joven y de sus amigos juerguistas al puerto de Pinares donde verán un eclipse se detiene para incluir una discusión intelectual sobre la vida y el arte entre él y Yiddy, su escéptico interlocutor británico. A través de la palmaria manipulación del material y de la estructura, Ayala llama la atención a la calidad ficticia del texto literario, contradiciendo la pretensión de documentación objetiva de la novela realista-naturalista. La inclusión de este tipo de divagaciones intelectuales, que podría parecer un intento de alejar al lector, constituye más bien un recurso narrativo para atraerlo y hacerlo participar activamente de la obra literaria brindándole la oportunidad -y la responsabilidad- de decidir el grado de relevancia de la información contenida en estos pasajes "prescindibles» y «superfluos».

Justamente, esta categoría de pasajes presumiblemente descartables es la que se relaciona con las disquisiciones filosóficas inclusas en muchas novelas noventayochistas. Amor y pedagogía (1902) de Miguel de Unamuno o El árbol de la ciencia (1911) de Pío Baroja son algunas de las obras que ejemplifican esta práctica, como indica Roberta Johnson (1993, p. 145-147). De esta categoría se puede destacar la intención paródica mediante la cual el autor asturiano se aleja pero también se acerca a la afición de los miembros de la llamada generación 
del desastre por la divagación ensayística que altera la trama del relato, si bien tal vez más por un afán lúdico que por fines intelectualizantes.

Es, empero, La pata la novela de la tetralogía que más se aproxima a ser una obra literaria sobre literatura; más específicamente, sobre leer y escribir textos literarios. Y vivirlos. Este rasgo se revela principalmente en los poemas que escribe Alberto y en la correspondencia que mantiene con su amigo Halconete. Revelar es el verbo idóneo para referirse a las conexiones intertextuales que plantea Ayala, consciente del aporte interconectivo que por su cuenta ha de realizar el distante lector. Al día siguiente de la borrachera con que termina Tinieblas y comienza La pata, Alberto despierta con una resaca iconoclasta que lo lleva a destruir muchos de sus libros y, decepcionado por «la enorme ridiculez del arte», también sus obras plásticas (O.C., vol. 1, p. 247).

Paso seguido, en lo que en términos gráficos -o sea, en términos del aspecto que presenta el texto en las páginas de un libro- se asemeja a un collage del innovador arte visual de principios del siglo XX, el lector puede apreciar "papeles, no muy claros en verdad; citas, notas, esbozos fragmentarios y versos» de Alberto (ibid., p. 265). En medio de un ambiente seudohoraciano y rodeado de sus mascotas, su perro Sultán y su gato Calígula, reflexiona sobre el morir y el nacer y luego escribe desordenados poemas que más parecen fábulas por la temática zoológica. Los nombres de sus dos mascotas, el de Madama Comino, una hormiga, y el de Alectryon, un gallo, sirven de títulos de estos versos. En dichas composiciones se alterna lo inane (la presencia de estos animales como fáciles representaciones de las debilidades humanas) con lo profundo, por ejemplo, sus comentarios, con ecos de la frase pascaliana -la cual sirve de epígrafe a la novela (ibid., p. 239) - acerca de la maldición humana de tener conciencia del universo y de la muerte. El ser humano contrasta con Madama Comino, a quien, como se diría coloquialmente, le importa un comino ese tipo de fabulaciones: «Eres dichosa porque nunca miras al cielo/ No sabes del bien ni del mal./ No sientes melancolías/ni la horrible desolación/del que ve que se acaban sus días/ y en su boca se hiela la canción./ Y esto no obstante...» (ibid., p. 272).

En el prólogo/epílogo de Tinieblas, a través de las preocupaciones de vanidad autorial que el moribundo Plotino Cuevas le revela al Padre X, Ayala satiriza lo que prevé los críticos dirán de su obra para así anular de antemano las impugnaciones de los mismos (ibid., p. 231-236). Entretanto, en «Madama Comino» hay un verso que captura eficazmente esta actitud burlona ante la crítica: «¡Yo pedante/ porque digo propincuo?» (ibid., p. 271). La extraliteraria impugnación de pedantería no se la achacan sólo sus coetáneos sino también muchos críticos a través de las décadas ${ }^{5}$, hecho que demuestra lo acertado de los comentarios anticipativos del autor asturiano. Para apreciar cabalmente el alcance lúdico de dichos comentarios, fíjese la atención en la ya mencionada analogía humano-animal de estos poemas, cabalmente el de la hormiga ignorante de su propia existencia.

5. Macklin ofrece un ejemplo de ello (The Window, 1988, p. 69). 
Se podría decir que estas composiciones chusco-serias refuerzan la ambivalencia de la lectura paródica de éstos y otros textos que se entrelazan en esta parte de la historia, rasgo que alcanza ribetes de mayor absurdidad en las cartas que Alberto le escribe a Halconete, contándole las aventuras que tiene como miembro del circo ambulante de un tal Míster Levitón (ibid., p. 324-351). En este pasaje, rebosante de alusiones a otros textos a través del protagonista convertido en un deambulante aventurero, se homenajean tanto al género picaresco como a su antípoda, el caballeresco. Por ejemplo, previo a empezar sus afanes circenses y epistolares, el muchacho teatralmente hiperestésico de Tinieblas es reemplazado por el despreocupado joven de este pasaje de La pata, más afín al Ramón que firma las cartas juveniles que el autor asturiano le envía al amigo de siempre, Miguel Rodríguez-Acosta (1980, p. 37-74). El nuevo Alberto le pregunta a su criado Manolo si quiere "seguir sirviéndole y vagabundear a la aventura» (O.C., vol. 1, p. 332). Dicho de otro modo, el señorito quiere saber si el criado estaría dispuesto a actuar de Sancho Panza para un Don Quijote moderno dedicado no a caballero andante sino a titiritero y tamborilero. Manolo no acepta y el sedicente quijote de entresiglos marcha sólo, decidido a reescribir no tanto la irreproducible novela de su admirado Cervantes, sino el motivo literario del viaje como símbolo del decurso de la vida y del aprendizaje que vertebra la picaresca desde sus inicios con Lazarillo de Tormes. En este sentido, dicho pasaje constituye una entreverada evaluación paródica de temas y figuras descollantes en la literatura clásica espańola.

La primera carta que Guzmán le manda a Halconete principia con un poema monorrimo que recuerda, de modo deliciosamente juguetón, los de Gonzalo Berceo, remontándose al medioevo:

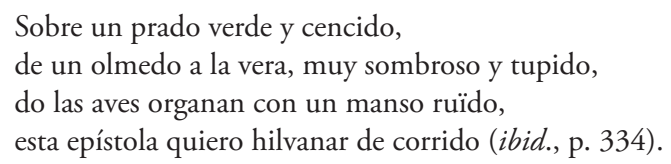

Pronto sus divagaciones literarias derivan en un comentario sobre la banalización de la literatura y la filosofía en una época más preocupada por la comercialización de todo producto, incluso el de índole cultural e intelectual. Según Alberto en el mundo moderno los nombres de Carlyle y Emerson se utilizan con el fin de promocionar tabaco y en la caja del producto se los ve frente a frente (ibid., p. 335). Casi mil años de la relación escritor-lector se resumen lúdicamente en un par de cartas, pasando de la poesía de Berceo, vista como la manifestación de una remota época menos complicada y más íntima, a la conversión capitalista de las letras y de sus exponentes en productos comerciales.

Esta porción epistolar de la novela y por ende, la aventura de Alberto-autor, acaban abruptamente cuando Alberto-titiritero monta una «farsa teológicalógica y empíreo-acrobática» no bien recibida por las autoridades de un poblado (ibid., p. 350). Si bien la infundada acusación de haber asesinado a una de las 
prostitutas acompańantes de los juerguistas en la novela anterior que le endilgan en la comisaría del poblado lo molesta, tener que revelar su identidad legal tras haber vivido de incógnito por una temporada, lo frustra sobremanera. Todos se enteran de la identidad de señorito de Pilares que había escondido celosamente tras los papeles literario-circenses que venía representando exitosamente, marcándose el final de sus despreocupadas aventuras literario-existenciales.

El impulso lúdico e innovador de Pérez de Ayala no se limita a la literatura y a la filosofía ya que también trata paródicamente textos religiosos como Ejercicios espirituales de San Ignacio de Loyola en la polémica novela cuyo título completo es A. M. D. G. La vida en los colegios de jesuitas. A causa del presumible anticlericalismo de esta obra, sobre todo del antijesuitismo de la misma, por muchas décadas se prohíbe su reproducción en España; incluso es excluida de la edición de Obras completas de $1964^{6}$. Esta novela puede leerse tanto a nivel intertextual (la conexión con la obra ignaciana) como a nivel extratextual o extraliterario, esto es, como una reflexión acerca del sistema educativo español, más específicamente de la educación ofrecida en las escuelas jesuitas que el mismo Ayala recibiera de niño. En suma, en esta narración llena de detalles autobiográficos, el autor asturiano explora el jesuitismo como institución y, principalmente, analiza el discurso ignaciano como texto.

Huelga puntualizar que la aproximación de Ayala a todos los ámbitos de la experiencia humana se caracteriza por la observación crítica. De ahí que no debería sorprender que la representación del sistema educativo religioso y la caracterización de la mayoría de los clérigos del colegio a que asiste Bertuco, la cual remite intertextualmente a la estética quevediana patente en la inolvidable figura del Dómine Cabra, reflejen esta actitud impugnadora. Valgan como ejemplos el padre superior Arostegui, quien dirige la institución con eficacia militar y el padre Mur, su lugarteniente, quien aterroriza al estudiantado con su nefasta personalidad. Desde la óptica desarmadora de Ayala, los sacerdotes que habitan la escuela jesuita a que asiste Bertuco cometen las mismas faltas e incorrecciones humanas que los ciudadanos que viven afuera, de aquí que los pecados capitales se noten en todo su grotesco y ridículo esplendor en el comportamiento y las ideas de propios y extraños. A los jesuitas se los describe como violentos, hipócritas, envidiosos, lascivos (hay un sacerdote pedófilo, el padre Echevarría) e ignorantes, es decir, humanos, demasiado humanos. Descuidan también la higiene personal, algo que repugna a los niños. Este desaseo podría verse como el encomiable rechazo a la vanidad mundana si no fuera por la detestable altivez de muchos de ellos, la cual evita que se den cuenta de su antihigiénica ridiculez. En la obra de Ayala desde sus comienzos se advierte la ausencia de personajes completamente malos o buenos, dando lugar a un universo no maniqueo habitado más bien por criaturas tragicómicas. A. M. D. G. también muestra este rasgo que realza la excepcionalidad de la extrema maldad de Mur, el cruel torturador de Bertuco.

6. El discutible anticlericalismo perezayalino es examinado por Rivas Andrés (1983), Prieto Jambrina (1999, p. 101, 105) y Amorós (1972, p. 160-163). 
Para Ayala, entonces, las instituciones educativas y religiosas revisten los mismos problemas y conflictos que las instituciones laicas en la España de la Restauración, siendo la más importante su falta de representatividad, o sea, de íntima identificación con la gente. Sea como fuere, el ataque de Ayala no es teológico ni personal, sino más bien político, un ataque político a las instituciones tradicionales de su país, señaladamente, la educativa, la religiosa $y$, valga la redundancia, la política. Acaso sea ésta una de las causas por las que sufriera el descarnado contraataque de la censura. Se trata de una embestida vengativa tan severa como injusta ya que el ataque de Ayala es vehemente pero no necesariamente anticlerical, pues él mismo critica el anticlericalismo a través de su mordaz pintura de "El pulpo», chocarrero órgano de prensa antijesuita que más que reportar se dedica a difundir el desprecio hacia la Compañía (1984, p. 173).

El saldo de la representación de la Compañía que realiza Ayala, empero, no es del todo negativo. Por ejemplo, el padre Sequeros, joven sacerdote bienquisto por los niños, especialmente por Bertuco, es «[u]n jesuita de verdad» (ibid., p. 127). También el padre Atienza (de quien se ha dicho representa a Cejador, amigo y maestro del asturiano), «aquel varón santo y desenvuelto, excelente en doctrina y en virtud» (ibid., p. 156), encarna la calidad humana del hombre religioso «de verdad».

El padre Atienza es el personaje que realiza los comentarios más significativos sobre la doctrina y el discurso ignacianos. Sus comentarios justifican la inclusión de Ejercicios espirituales en un libro presumiblemente antijesuita pues a través de la actitud y las ideas de este personaje Ayala acaso intenta rescatar lo que considera el verdadero espíritu ignaciano de acción y tolerancia, contenido principalmente en esa especie de manual de vida. Para explicarle al padre Ocańa lo peligroso pero no herético de la propensión a la abstracción idólatra que exhibe el padre Sequeros, Atienza reflexiona del modo siguiente:

Sabes que en la Iglesia de Cristo, a partir ya de San Pedro y San Pablo, se manifiestan dos porciones, como las valvas de una concha, una espiritualista y otra materialista. Nuestra sociedad, no lo dudes, trajo nueva substancia a la valva materialista. Atiende a los Ejercicios de San Ignacio, a la manera que tiene de hacer intervenir las potencias del alma en la meditación; la composición de lugar, o sea la materialización del espíritu, es lo primero y es el todo, en rigor porque de esta suerte, en lugar de elevarnos de golpe, y con evidente riesgo, claro está, a las huecas y cristalinas regiones de lo inefable, permanecemos asidos a lo sensible, a lo tangible y concreto [...] Con lo cual no parece sino que San Ignacio se propuso dar un gran sentido práctico a su Compañía, un impulso de acción, y al mismo tiempo, alejar a sus hijos del grave peligro de aletazos inútiles en la abstracción pura (ibid., p. 183-184).

En uno de los capítulos prescindibles empleados por Ayala para detener la fluidez de la trama y fragmentar la estructura de la obra, el padre Olano dirige los ejercicios enfatizando sólo su aspecto más groseramente material(ista) como parte de un espectáculo diseñado para lograr que los niños se arrepientan de sus pecados y rueguen, angustiados, por su salvación. La lectura de meditaciones está acompañada de la tramoya «de las comedias» en forma de elaborados 
efectos de sonido y de duras sesiones de confesión escenificadas en penumbras con la finalidad de producir un ambiente sobrecogedor (ibid., p. 236). Resulta impactante la profunda inseguridad, el desprecio a la religión y el blasfemo cuestionamiento de Dios que el desdichado Bertuco expresa en su diario a raíz del pavor que siente tras los ejercicios (ibid., p. 325-332). Los Ejercicios, pensados por Loyola para fortalecer al creyente, se usan para debilitar a los impresionables alumnos y lograr que se rindan a la autoridad. Ello se logra primordialmente mediante la lectura incompleta de los mismos, puesto que, según la explicación de Ayala, de sus tres vías, la purgativa (de orden punitivo), la iluminativa (de orden educativo y cognitivo) y la unitiva (de orden edificante y altamente espiritual), sólo la primera se considera relevante para los nińos (ibid., p. 237).

No obstante, más que criticar el texto ignaciano, Ayala destaca lo que tacha de lectura errada del objetivo y del espíritu de los Ejercicios. Esta distinción clave se efectúa al final de $A . M . D$. G. Bertuco, el padre Atienza y otros se dirigen a Pilares, alejándose definitivamente de la escuela y, acaso, del jesuitismo. Cuando le preguntan a Atienza si piensa «que se debería suprimir la Compañía de Jesús», él responde lo siguiente: «De raíz» (ibid., p. 343). La respuesta que ofrece este buen hombre subraya su frustración a la tergiversación de la doctrina y del texto ignacianos pero no su rechazo ni a aquélla ni a éste. En otras palabras, él es capaz de distinguir entre el discurso y el espíritu originales del jesuitismo y la institución presente que los tergiversa. Es muy probable que Ayala no se opondría, con la finalidad de destacar esta diferencia, a la colación de la segunda anotación de los Ejercicios en la que se aconseja que el orientador sea breve y deje que el orientado piense por sí mismo, racionalmente o por divina intervención, sobre el material estudiado, en lugar de intentar imponer un único sentido, debido a que es mucho más satisfactorio lo que uno mismo devela (Ejercicios espirituales, p. 154). Esta socrática anotación ignaciana indubitablemente no se aviene al adoctrinamiento impositivo de Olano. El texto perezayalino, pues, constituye asimismo un sugestivo comentario acerca de la relación autor-textolector, con la añadidura de un aspecto más bien inherente al texto teatral: la escenificación. Habida cuenta de tal aspecto, se podría afirmar que la culpa de la dolorosa reacción de Bertuco y de la mayoría de sus condiscípulos la tiene el director de escena y no el autor del texto. En rigor, Bertuco ni llega a leer la obra de Loyola sino que asiste a la interpretación que de ésta lleva a cabo un escenificador con palmarias limitaciones.

A través de esta diferenciación Ayala sugiere que la manera en que Olano lee los Ejercicios, manera aceptada por la Compañía de la época, no es la correcta y que hay otros modos de leerlos con mayor eficacia. Es evidente, empero, que Ayala no procura convertir su texto en un instrumento impositivo como Olano. Contrariamente, su novela exhibe un cariz lúdicamente transgresor ajeno a la imposición que se puede apreciar, paradójicamente, en la sobredicha segunda anotación de Loyola, mediante la cual se le otorga al lector, esta vez sin intermediario escenificador, la oportunidad de analizar y de interpretar por sí mismo. Esto implica que el mismo texto perezayalino conlleva elementos 
que posibilitan que el lector lo trascienda desarmándolo como el niño schilleriano con un juguete nuevo. $\mathrm{O}$ sea, el mismo texto posibilita que se lo lea incorrectamente, lo que convierte a $A . M$. D. G. en una lectura errada del texto ignaciano efectuada por Ayala. Tal lectura propicia, a su vez, que ambos textos, e incluso la tradición literaria y cultural en que surgen, puedan ser leídos erradamente, produciendo un sinnúmero de posibles interpretaciones, la mayoría de ellas seguramente impensadas por el propio autor.

Por lo expuesto hasta aquí podría decirse que $A$. M. D. G. tipifica la modernidad del texto novelístico perezayalino. En un artículo en que discute Ejercicios espirituales de Loyola y su conexión con Maurice Barrès (1862-1923), un autor francés leído por Ayala, Michel Beaujour pregunta retóricamente lo siguiente, fungiendo de lector tradicional ante una novela moderna: «Why are (modern) novels disorderly, transgressive, and dirty?» (1980, p. 347). La primera característica se evidencia en la forma fragmentada y de collage de la novela en cuestión, mientras que la explícita invitación a jugar con el texto e ir más allá de las expectativas y las normas, ilustra la segunda. En cambio, resulta problemático fijar la tercera característica en términos netamente diegéticos puesto que son pocas las descripciones que pudieran considerarse soeces en la narrativa de Ayala. Las pocas que hay se antojan mucho menos escabrosas que las encontradas en algunas obras de la época, incluso en la propia Tinieblas, el relato más atrevido de la producción perezayalina.

Quizá lo «sucio» o censurable deba buscarse en la intertextualidad, pero no en las conexiones entre textos sino en la interpretación moralizante de la manera en que Ayala se apropia de un texto religioso, ciertamente irreverente para la ortodoxia religiosa y el tradicionalismo cultural de la era y allende. Victoriano Rivas Andrés refiere los supuestos intentos de Ayala de mostrar su arrepentimiento por haber escrito tal obra (1983, p. 272). Para probarlo cita una entrevista en que se indica que Ayala presumiblemente admite lo siguiente sobre $A$. M. D. G: «es una travesura de mi juventud, cuando yo volterianizaba un poco para asustar a las beatas de Oviedo» (ibid., p. 261). Aunque probablemente nunca se sepa la verdad acerca de este episodio es llamativo que Rivas Andrés semeje estar sinceramente interesado en presentar a un Pérez de Ayala arrepentido, mostrándose más preocupado por la salvación del alma del autor asturiano a causa de su blasfema irreverencia que por su obra literaria. (Ahora bien, acaso se deba considerar esta lectura más moralista que literaria un ejemplo de cómo se puede leer erradamente el texto perezayalino.)

En Troteras, la siguiente y postrera novela en el ciclo de Alberto, Ayala problematiza, acaso con mayor ahínco que en los otros segmentos de la tetralogía, las convenciones en torno a la autobiografía, así como la supuesta capacidad mimética de reproducir de modo directo una realidad que antecede al texto literario. Ambas problematizaciones se confunden en el hecho de que Alberto Díaz de Guzmán, supuestamente el protagónico portavoz autorial, es eclipsado por varios personajes del mundillo bohemio de la época a tal punto que se convierte en una figura ficticia secundaria sin ninguna autoridad dentro del texto. Si bien el desdichado Teófilo Pajares, bufo trasunto del poeta modernista 
Francisco Villaespesa (Amorós, 1972, p. 207, 219), cobra mayor protagonismo que Alberto, el miembro más colorido de este ambiente es Alberto MonteValdés, quien destaca por sus excentricidades, su estrambótico aspecto y su azarosa existencia ${ }^{7}$. Esta criatura tragicómica también reviste interés porque, se supone, es el calco literario de Ramón del Valle-Inclán.

Aun cuando muchas de las aventuras y desventuras del excéntrico MonteValdés tienen su correlato en verificables anécdotas de Valle-Inclán, el deforme y paupérrimo hombrecillo de la novela llama la atención por la humorística presentación de su carácter asocial y extravagante, independientemente de la posible existencia de un modelo extraliterario. Ello se debe ante todo a que es presentado como una figura tragicómica mediante el explícito enlace intertextual con Don Quijote. Del mismo modo, Guzmán destaca no tanto por ser un producto autobiográfico de Ayala sino por su antedicha conexión con los personajes jóvenes de muchas novelas noventayochistas o con el mismo Don Quijote en La pata. Pajares, por su parte, sobresale por ser una encarnación del modelo literario y popular del bohemio decadente finisecular y no necesariamente por representar a Villaespesa.

Con respecto a don Alberto, desde la primera escena en que se presenta se sabe que es un personaje distinto. Tras un bullicioso desencuentro entre Pajares y la portera del edificio donde reside Monte-Valdés (O.C., vol. 1, p. 474478), aparece la figura de éste de manera cómica: «A la primer [sic] ojeada este hombre ofrecíase como el más cabal trasunto corpóreo de Don Quijote de la Mancha» (ibid., p. 479). Luego se hace referencia a sus peripecias literarias, verbigracia, no consigue publicar nada, y al poco respeto que le dispensan sus colegas. Sin embargo, a diferencia del manchego, este «moderno» Quijote es un hombre de letras y no de armas a quien no le interesa ayudar a nadie porque sabe bien que no puede ni ayudarse a sí mismo. Su perdición no es el arte literario en general, sino más bien su propio arte; él no lee, sino que escribe. No lucha contra gigantes sino contra cupletistas. Esta su lucha tan personal se nota en el pasaje con La Ínigo, fornida cupletista y su jurada enemiga. Poco antes de salir al escenario durante una velada a que asiste todo el mundillo bohemio madrileño, ella lo insulta. Monte-Valdés la sigue enfervorizado y le propina un furibundo patadón en las nalgas (¡con su pata de palo!), delante de todo el público que piensa que aquello forma parte del espectáculo. El delirante episodio finaliza del modo siguiente: "[e]ntre seis hombres la habían llevado pataleando y echando espuma por la boca» (ibid., p. 654).

Justamente este episodio evidencia que la vida de don Alberto Monte-Valdés y de otros personajes, incluso la de Alberto Díaz de Guzmán, es hilarantemente absurda, hiperbólica, patética, vale decir, esperpéntica, dentro del ambiente desenfrenado, excéntrico, aciago y frustrante del submundo bohemio de la España intersecular según la muy particular perspectiva de Ayala. El autor asturiano, empero, no insiste en que su representación de la época, de sus

7. Para una discusión sobre las figuras históricas representadas en Troteras léase a Thomas R. Franz (1996, p. 432) y a Amorós (1972, p. 206-209). 
coetáneos y de sí mismo deba considerarse una recreación fehaciente e indiscutible de la realidad extratextual sino que se la aprecie como parte del complejo juego lectorial que propone en torno al texto literario.

\section{LEYENDO AL AUTOR Y SU OBRA}

Este análisis de la primera etapa de la producción de Ayala, llámese autobiográfica o de exploración, muestra, en primer lugar, la intención lúdica de su arte, evidente en su modo de jugar, a través de innovadores recursos narrativos, con las expectativas de univocidad y de acabamiento textuales que seguramente posee el lector, especialmente el lector pasivo. Es que Ayala desea entablar una relación con un lector activo y moderno que perciba la calidad multívoca, abierta y artificial del texto literario, un lector cuya labor coautorial constituye un elemento indispensable pero a la vez imprevisible para la labor del autor debido a la insalvable distancia que separa al uno del otro. En segundo lugar, el presente análisis muestra que la parodia -habida cuenta de la explicación etimológica de este concepto que revela su calidad ambivalente- puede ser un instrumento para arrostrar la ansiedad de la influencia que siente el autor recién llegado a la escena literaria porque expresa tanto avenencia como desavenencia con lo anterior, lo coetáneo e incluso lo por venir.

Para apreciar debidamente la ambivalencia implícita en la parodia es necesario fijarse en la actitud crítica que vertebra el juego literario perezayalino incondicionalmente desarmador, transgresivo, «sucio». O sea, se debe entender que para Ayala es menester leer a sus antecesores de modo errado con el fin de hallar su propio espacio en la tradición literaria espańola y alterarla enriqueciéndola con su flamante contribución. Sin embargo, a la vez, debe apreciarse su acercamiento a los que lo preceden, puesto que, al referirse a ellos, esto es, al estatuir una fructífera y respetuosa relación de afinidad más que de filiación con ellos, afianza también su conexión intertextual con dicha tradición. Además, la forma autobiográfica de muchos de los textos narrativos más salientes que Ramón Pérez de Ayala escribe entre 1902 y 1913 le ofrece la oportunidad de explorar la situación del yo, de su yo, dentro de la tradición literaria de donde surge y a la que aporta sus propias creaciones. Es la situación del yo de un autor moderno, disperso en el texto literario que lleva su nombre pero no contiene su cuerpo, invitando al lector a que lea errada y paródicamente tanto al escritor como su obra. 


\section{Obras Citadas}

Amorós Andrés, La novela intelectual de Ramón Pérez de Ayala, Madrid, Editorial Gredos, 1972.

Beaujour Michel, «Exemplary Pornography: Barrès, Loyola, and the Novel», The Reader in the Text. Essays on Audience and Interpretation, Ed. Susan Suleiman \& Inge Crosman, Princeton, New Jersey, Princeton University Press, 1980, 325-349.

Bloom Harold The Anxiety of Influence, New York, Oxford University Press, 1997.

Bobes Naves María del Carmen, «Renovación del relato en las primeras novelas de Don Ramón Pérez de Ayala», Pérez de Ayala visto en su centenario: 1880-1980, Oviedo, Idea, 1981, 71-97.

Franz Thomas R., "Tiempo de silencio and its Cela-like Resonances of the Generation of 1898", Hispania 79, 1996, 429-438.

Friera Suárez Florencio, Ramón Pérez de Ayala, testigo de su tiempo, Gijón, España, Fundación Alvargonzález, 1997.

Johnson Roberta, Crossfire, Lexington, Kentucky, The University Press of Kentucky, 1993.

Lelièvre F. J., "The Basis of Ancient Parody», Greece and Rome, 2nd ser. 1.2, 1954, 66-81.

Loyola San Ignacio de, Ejercicios espirituales, Obras Completas, Madrid, Biblioteca de Autores Cristianos, 1952.

Lozano Marco, Miguel Ángel, Del relato modernista a la novela poemática: la narrativa breve de Ramón Pérez de Ayala, Alicante, Universidad de Alicante, 1983.

Macklin, J. J., The Window and the Garden: the Modernist Fictions of Ramón Pérez de Ayala, Boulder, Colorado, Society of Spanish-American Studies, 1988.

Pérez de Ayala Ramón, A. M. D. G. La vida en los colegios de Jesuitas, Madrid, Cátedra, 1984.

- Cincuenta años de cartas intimas a su amigo Miguel Rodríguez-Acosta (1904-1956). Ed. Andrés Amorós, Madrid, Editorial Castalia, 1980.

- El último vástago. Hojas Selectas, 4 (1905).

- Obras Completas, 4 vols., Madrid, Aguilar, 1964.

- Pequeños ensayos, Madrid, Biblioteca Nueva, 1963.

- Sonreía. Obras Completas, Vol. 1, Madrid, Aguilar, 1964, 817-857.

- Trece dioses: Fragmentos de las memorias de Florencio Flórez, Ed. Geraldine M. Scanlon, Madrid, Alianza Editorial, 1989.

Prieto Jambrina Juan Ramón, El humanismo armónico de Ramón Pérez de Ayala, Alicante, España, Universidad de Alicante, 1999.

Rivas Andrés Victoriano, La novela más popular de Ramón Pérez de Ayala. Anatomía de A. M. D. G., Gijón, Gráficas Apel, 1983.

Scanlon Geraldine, "Trece dioses. Novela perdida de Pérez de Ayala», Ínsula, 503, 1988, 28. 